\title{
First two cases of gnathostomiasis in Sri Lanka
}

\author{
S Samarasinghe ${ }^{1}$, B J C Perera ${ }^{2}$ and B G N Ratnasena ${ }^{3}$ \\ (Index words: Human subcutaneons gnathostomiasis, eosionphilia, recovery of complete larvae)
}

\section{Introduction}

Although it is a common infestation in the Asian region, human gnathostomiasis due to the third stage larvae of Gnathostoma species has not been reported in Sri Lanka up to now (1). The definitive hosts of this nematode are felids and canids, the former being particularly important. Humans are aberrant hosts and the disease is characterised by peripheral eosinophilia and a variety of local manifestations such as migratory swellings and inflammation of visceral organs. We report the first two cases of human gnathostomiasis in Sri Lanka.

\section{Case 1}

A 4-year old boy was admitted to the Lady Ridgeway Hospital for Children, Colombo, with a history of fever, cough, wheezing, abdominal pain and intermittent localised swellings of the body of 3 months' duration. The swellings were itchy and tender. They were migratory and usually just one swelling occurred at any given time. The ESR was 76 $\mathrm{mm}$ in 1 hour. The white cell count was $12.5 \times 10^{9}$ per litre with an absolute eosinophil count of $3.5 \times 10^{9}$. A provisional diagnosis of cutaneous larva migrans was made and the child was treated with albendazole. While on treatment, the mother was able to pick a worm extruding from a subcutaneous lump in the right side of the back of the chest. The worm was sent for parasitological examination to the Medical Research Institute.

The child is a resident of Chilaw on the western coastal belt of Sri Lanka, and had never been out of the country. He cooked fresh water fish. He drinks unboiled water from a domestic well. He was not given any specific treatment and he remained well on subsequent follow up.

\section{Morphology of the worm}

The length of the two worms were $3.5 \mathrm{~mm}$ and $3 \mathrm{~mm}$. The maximum width of both worms was $0.5 \mathrm{~mm}$. The head bulbs showed 4 rows of hooks, the first and fourth rows being slightly smaller (Figure). There were tri-lobed lips, and a short thick reddish ventrally curved body covered with cuticular spines. had a pet cat at home. The mother admitted that she had given him partially boiled fresh water fish at times and unboiled water taken from a domestic well. On subsequent follow up visits he remained well and the eosinophil count came down to the normal range.

\section{Case 2}

A 48-year old man was admitted to the Chilaw Base Hospital with an 8-month history of intermittent fever, cough abdominal pain and migratory subcutaneous swellings of the body. His wife brought a worm extracted from the tip of his right index finger. His ESR was $116 \mathrm{~mm}$ in 1 hour. The white cell count was $9.5 \times 10^{9}$ per litre with an absolute eosinophil count of $4.2 \times 10^{9}$. The worm was sent to the Medical Research Institute for parasitological evaluation.

He is a carpenter who had never left the country. He had been resident in Chilaw all his life. He admitted that he had eaten partially

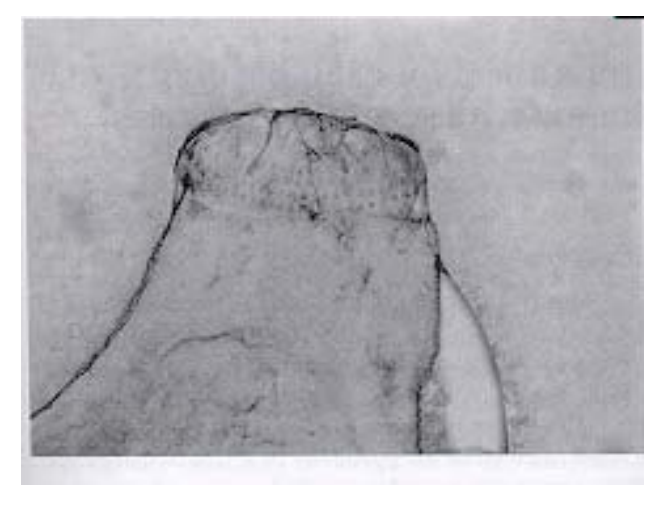

Figure. The head bulb of one worm showing hooks and tri-lobed lips.

\section{Discussion}

The third stage larva of the nematode Gnathostoma causes human gnathostomiasis. The adult worm usually inhabits the stomach wall of felines or canids. The life cycle requires passage through two aquatic hosts. The first of these is Cyclops followed by a variety of fresh water fish that feed on infected Cyclops. Human infection occurs mainly by ingestion of raw or partially cooked fresh water fish. Drinking unboiled water containing infected Cyclops may be another source of infection.

In the two cases documented in this report, the appearance of the head bulb and the arrangement of the

\footnotetext{
${ }^{1}$ Medical Parasitologist, Medical Research Institute, Colombo, ${ }^{2}$ Paediatrician, Lady Ridgeway Hospital for Children, Colombo and ${ }^{3}$ Surgeon, Base Hospital, Chilaw, Sri Lanka. (Received 23 January 2002, revised version accepted 26 May 2002. Correspondence BJCP, email: bjcp@sltnet.lk telephone +94 1 863265. Competing interests, none declared).
} 
hooks in the head bulb are characteristic of Gnathostoma spinigerum. The recovery of complete larvae from humans is very rare (2). Diagnosis depends on the morphology of crosssections and specific serology. Fortunately, in the two cases reported it was possible to examine the complete larvae with the characteristic appearance of the head bulbs and the arrangement of the hooks, confirming the diagnosis of infestation with Gnathostoma spinigerum.

In human infections, when the larvae migrate above the neck, there is the danger of invasion of the central nervous system. Furthermore, direct involvement of the eye may necessitate complete enucleation. When infest-ation occurs below the neck, it may cause pneumothoraces and peritoneal granulomata that may be mistaken for tumours. Hence it would be useful to be aware of the possibilty of this infection in Sri Lanka, especially in the region of Chilaw.

\section{Acknowledgements}

We thank Professor A S Dissanaike for advice, Mrs. C S Surige for processing the samples and Mrs. R A D M Jayanthi of the Photography Unit of the Postgraduate Institute of Medicine, University of Colombo, for the photomicrographs.

\section{References}

1. Dissanaike AS. Parasitic zoonoses in Sri Lanka. Ceylon Medical Journal 1993; 38: 150-4.

2. Markell EK, et al. Markell and Voge's Medical Parasitology. W. B. Saunders Company, Philadelphia. 1999; pp351-2. 